Gyancity Journal of Engineering and Technology,

Vol.5, No.1, pp. 26-33, January 2019

ISSN: 2456-0065 DOI: 10.21058/gjet.2019.51004

\title{
Tutorial for Deaf - Teaching Hindi Alphabet using Synthetic Animations
}

\author{
${ }^{1}$ Lalit Goyal, ${ }^{2}$ Vishal Goyal \\ ${ }^{1}$ Associate Professor, DAV College, Jalandhar \\ ${ }^{2}$ Associate Professor, Punjabi University, Patiala \\ 1'goyal.aqua@gmail.com, ${ }^{2}$ vishal.pup@gmail.com
}

\begin{abstract}
Developing an automatic tool for providing education to the people has become essential in today's world of information technology. For differently abled people especially in India where the resources are scarce for their education, it becomes essential to develop technologies which give the opportunity to each and every individual to get the education online and free of cost. Research work has been done to make an online tool accessible for learning Hindi language alphabet in their own Sign Language (language used by deaf people using hands, face expressions) which in India is Indian sign language. HamNoSys notation (written form of three dimensional sign) of atleast two words corresponding to each alphabet of Hindi Language is created. This HamNoSys notation when used in JASigning animation tool produces the synthetic animation rather than human video. The synthetic animations are better as compared to human videos in terms of memory consumption, standardization, and flexibility, and scalability. Synthetic animations can be modified as per the requirement whereas the human videos cannot be modified. The only drawback that seems is, these synthetic animations may lack the natural non-manual component of sign. The research work has been incorporated to produce the web portal that displays the Hindi alphabet along with the picture corresponding to that alphabet and the synthetic animation with which that word is signed in Indian Sign Language. A total of 66 words are used to produce the Signs in the web portal which corresponds to 33 Hindi alphabets. The research work is the first of its kind for Indian Sign Language.
\end{abstract}

Keywords: ISL, HamNoSys, SiGML, Hindi Alphabet, Synthetic Animation

\section{Introduction}

Sign language is the visual spatial language which is used by the differently abled hearing impaired people to communicate. Sign Language is the three dimensional language which uses the 3D space around the signer's body using its hands, arms, body postures, face expressions, and head movements.

Among approximately 7105 known living languages worldwide, there are 141 Sign Languages depending upon the region in the world. There are nearly 72 million people who are hearing impaired among nearly 7 billion people on earth. The situation is worst as $90 \%$ of these differently abled people have very limited or no access to education and other information. [1][2].

In India, situation is worse; there are 5072914 persons who suffer from hearing disability. Among them, only 546826 hearing impaired persons are literate below primary education [3] which accounts for only $10.78 \%$.

Sign language is different for different countries/regions as this language is not created but it is evolved by deaf people. So, depending on the region, the signs are different as well as the grammar is also different depending on the region. As far as Indian Sign Language is concerned, it is categorized as manual and non-manual signs which may be static signs or dynamic signs as shown in figure 1. Static signs are those signs which do not have any movement in their signs. The dynamic signs are those which use the 
movement of the hands, and the non-manual features of the sign. Most of the signs used in the Sign Language are dynamic signs.

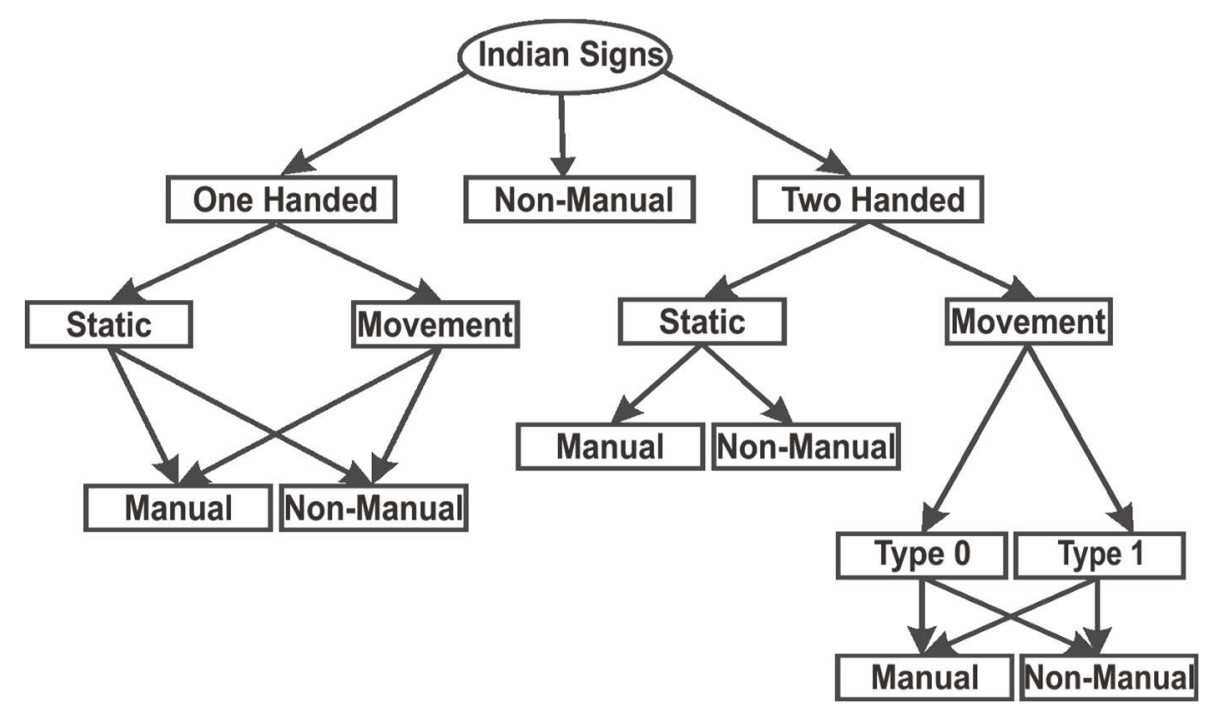

Figure 1. ISL Types Hierarchy

The one handed signs are represented by a single dominating hand whereas the two handed signs are represented by both the hands of the signer. Both, one handed as well as two handed signs can be either static or dynamic (having movements). Each of the static and movement signs is further classified into manual and non-manual signs.

Two handed signs with movements can be further distinguished as: Type 0 and Type 1 signs. Type 0 signs are those signs in which both the hands are active i.e. both the hands are in motion.Typel signs are those signs in which one hand (dominant) is more active as compared to the other hand (non-dominant).

\section{Review of Literature}

The education is essential for the better social life. The hearing impaired persons are also required to be educated so that they can communicate with each other in their own language as well as capable of communicating in their social life. In India, various schools are available to impart education to these people but these schools are limited to only urban areas. Even the number of schools is scarce in urban area. A lot of hearing impaired people have no access of education and so they are cut off from the society.

A lot of work has been done in implementation of sign language dictionary worldwide. Dictionaries have been created in the form of books which are obsolete now a day in the age of information technology. Video dictionaries are available for sign languages of many countries like America, Britain, Australia, Spain, Italy, and even India. These video dictionaries can be categorized as real character (human being) producing the sign or computer generated animated character (avatar) producing the sign. A lot of Indian sign language dictionaries are available which uses the real human being producing the sign for an English word. No Indian sign language dictionary is available which uses computer generated character (avatar) technology.

a) The Ramakrishna Mission collaborated with CBM International, Germany for a project on sign language dictionary in year January 1999. The goal for the project was to standardize Indian Sign Language. On November 24, 2001, the first Indian Sign Language dictionary was released which 
contains more than 2500 signs. These signs were taken from 42 cities in 12 States to provide a common sign language all over India[4]. The signs in this online dictionary are videos of real human. English Alphabets are also included in the sign dictionary. This dictionary does not contains any other languages of India even Hindi alphabets are not included.

b) Spread the Sign, an international project by Leonardo da Vinci supported by the European Commission through the Swedish International Program Office of Education and Training. The goal of this project is to share various sign languages from different countries over the internet. The drawback of this work is that it has videos for the words rather than animations which take a long time to load as compared to synthetic animations [5]. The participation of various countries is not upto the mark.

c) Handspeak is is a dictionary which is created for American Sign Language(ASL). The dictionary is released on the domain handspeak.com in 2000. The website contains the ASL signs, some variants of ASL signs, some verb inflections, and more. The dictionary is produced and signed by native ASL bilinguals [6].

d) Sign Smith [7] is a 3D illustrated dictionary of ASL. It is used as educational software for the hearing impaired people of America. It is also an authoring tool to create ASL content.

A lot of work is done in developing the dictionaries of sign language of various countries but no work has been found in developing the dictionary or tutorial for teaching the Hindi (National language of India) alphabet.

\section{Hindi Alphabet}

Hindi Language is collection of alphabets called Varn and this collection of varns is called Varnmala. There are 44 basic letters in Hindi Varnmala that can be divided into main two categories namely:

I. Vowels or swars

II. Consonants or vianjans

I. Vowels are called swar in Hindi. There are total of 11 vowels which are divided into two parts based on pronunciation:

a. Short Vowels: The vowels that take minimum time in pronunciation. These are also called MoolSwar or HasvSwar in Hindi. These are 4 in count out of 11 vowels:

अ इ उ ऋ

b. Long Vowels: The vowels that take twice the time than those of short vowels in Pronunciation. These are also called SandhiSwar or DiraghSwar in Hindi. These are 7 in count out of 11 vowels : आ ई ऊ ए ऐ ओ औ

II. Consonents are also called Vianhans. There are total 33 consonents which are divided into three parts:

c. Mutes or Saparsh

$\begin{array}{cc}\text { क ख ग घ } & \text { Kavarg } \\ \text { च छ ज झ ज } & \text { Chavarg } \\ \text { ट ठ ड ढ ण } & \text { Ttavarg } \\ \text { तथ ध ध न } & \text { Tavarg } \\ \text { प फ ब भ म } & \text { Pavarg }\end{array}$




\section{d. Semi-Vowel or Anthasth:}

$$
\text { य र ल व Anthasth }
$$

\section{e. Sibilants or Usham:}

Kavarg, Chavarg, Ttavarg, Tavarg, Anthasth, and Usham classification is based on the way these are pronounced or the place where they originates.

Four letters called sanjuktakshar that are not included into the Hindi Alphabet. Sanjuktakshar are the characters that are made from 2 or more consonants (vianjans). These letters are very commonly used in Hindi Language. So, consideration of these letters is must.

$\begin{array}{llll}\text { क्ष }= & \text { क् } & + & \text { ष } \\ \text { त्र }= & \text { त् } & + & \text { र } \\ \text { ज्ञ }= & \text { ज् } & + & \text { ज } \\ \text { श्र }= & \text { श् } & + & \text { र }\end{array}$

\section{Real Vs Synthetic Video Dictionaries}

Translation process from a source language to target language requires a bilingual dictionary between the source and target languages. In case of translating Hindi text to Indian Sign Language, bilingual dictionary of Hindi word and Indian Sign Language is required. Hindi-ISL bilingual dictionary is completely different from any other bilingual dictionary between the spoken languages. The reason behind is that the Indian Sign Language is the visual spatial language which cannot be spoken or written. So, irrespective of bilingual dictionaries of other spoken languages, for each Hindi word, the corresponding ISL word is not the written word. Here, the Hindi word's counterpart in ISL can be a real human video, sign picture, coded sign language text, or synthetic animation. All the approaches have their own pros and cons but the synthetic animations are well suited because of scalability of computer generated avatar. A comparison of all the media used for creating the bilingual dictionary of English-SL has been given in the Table 1:

Table 1. Comparison of Different Media used for Creating Bilingual Dictionary

\begin{tabular}{|c|c|c|}
\hline Media Type & Pros & Cons \\
\hline Video Signs & $\begin{array}{l}\text { f. Realistic } \\
\text { g. Easy to create }\end{array}$ & $\begin{array}{l}\text { - Time consuming to create } \\
\text { - High memory consumption } \\
\text { - Not supported by translation system }\end{array}$ \\
\hline Pictures & Very less memory consumption & $\begin{array}{l}\text { - Time consuming to create pictures } \\
\text { - Not realistic as compared to videos } \\
\text { - Not supported by translation system }\end{array}$ \\
\hline $\begin{array}{l}\text { Coded SL Text (written } \\
\text { form of SL) }\end{array}$ & $\begin{array}{l}\text { - Minimal Memory consumption } \\
\text { - Supported by translation system }\end{array}$ & $\begin{array}{l}\text { - Very difficult to read and understand } \\
\text { - Required to be learnt }\end{array}$ \\
\hline Synthetic Animations & $\begin{array}{l}\text { - Very less memory consumption } \\
\text { - Can be easily reproduced } \\
\text { - Supported by translation system } \\
\text { - Avatar can be of any choice }\end{array}$ & - Not as realistic as human videos. \\
\hline
\end{tabular}




\section{HamNoSys Notation}

ISSN: 2456-0065 DOI: 10.21058/gjet.2019.51004

Sign Language is a three dimensional language which cannot be written just like the other spoken languages like English, Hindi, Punjabi etc. But, researchers have created various writing notations of sign language. The benefit of writing notation is that the translation process from a spoken language to sign language becomes feasible. Even a writing notation of sign language is must for creating the computer generated character (Avtar) that can be animated just like the human being. Various writing notation available for writing the sign language are Bébian Notation, Stokoe Notation, Gloss Notation, Hamburg Notation System (HamNoSys), SignWriting (SW), si5s, SignFont, SignScript, SLIPA etc. We have used HamNoSys notation to create the animation of the words related to Hindi alphabet.

The Hamburg Notation System (HamNoSys) is a phonetically based notation system that was developed by Siegmund Prillwitz in 1984[8] at the institute of German Sign Language, University of Hamburg. HamNoSys notation is rooted in the Stokoe notation with more detail handling the non-manual component of the sign. Around 200 symbols are available in this notation system to describe any sign. The structure of this notation contains mainly four components: Symmetry operator (in case both the hands are used), NMF (to describe the non-manual features), Initial Configuration (contains in sequence the hand shape, hand orientation, and hand location), and Action/Movement (the dynamic part or movement of the hands)

The syntax of HamNoSys notation is the sequence of symbols of symmetry, non-manual features, hand features (hand shape, orientation, location) and at last, the hand movements. Figure 2 shows the basic structure of the HamNoSys notation. The first component of HamNoSys notation is always the symmetric operator which is used for producing two handed signs. The second component is for non-manual part of the sign such as face expressions, head movement, body movement, and lips movement (for getting the phonetic expression). The third component is for hand shape, hand orientation, and hand location. The forth component of the notation is the movement of the hands in case of dynamic signs. Figure 4 shows an example of English word 'Beautiful' in written form "HamNoSys".

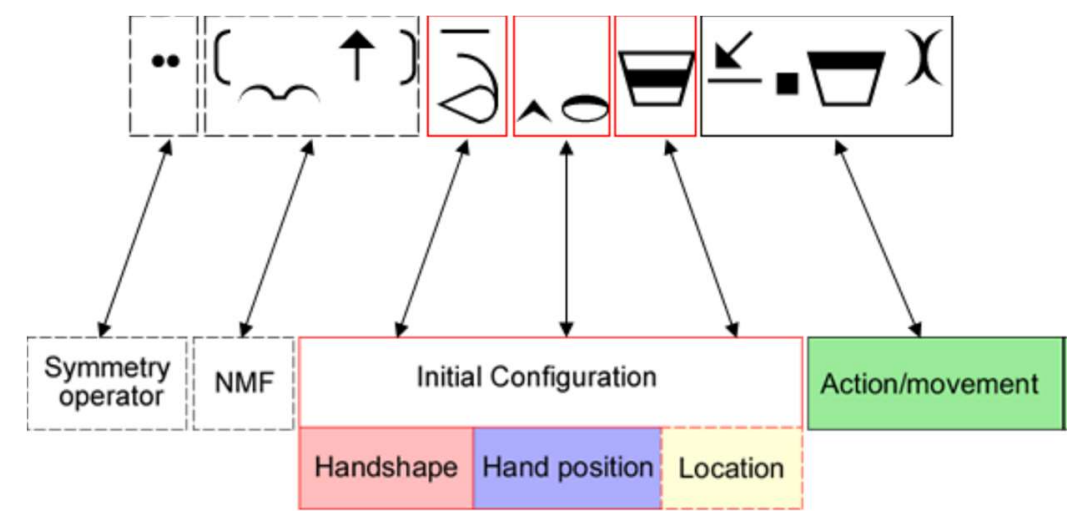

Figure 2. Structure of the HamNoSys

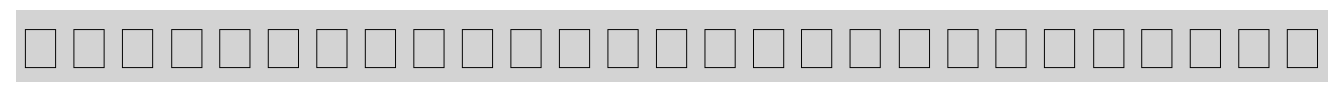

Figure 3. HamNoSys Notation for word "Beautiful"

An advantage of HamNoSys is that it is international and can be used to write any Sign Language. This notation system was initially handwritten, but a machine readable Unicode is now available from the University of Hamburg. This notation is iconic, has a formal syntax as shown in Figure 3 and can be stored in a computer database. The limiting part of this notation is that it does not provide an easy way to describe 
non-manual features, such as facial expressions and body movements but still the non-manual part produced by using this notation is comparatively better than other available SL writing notations.

An XML encoding of HamNoSys called Signing Gesture Markup Language (SiGML) is also available. SiGML encoding is used to produce the animation of the sign using an animation tool JASigning [11]. It was developed for the ViSiCast project by Richard Kennaway [9]. Some of the symbols used in HamNoSys notation are shown in Figure 4.

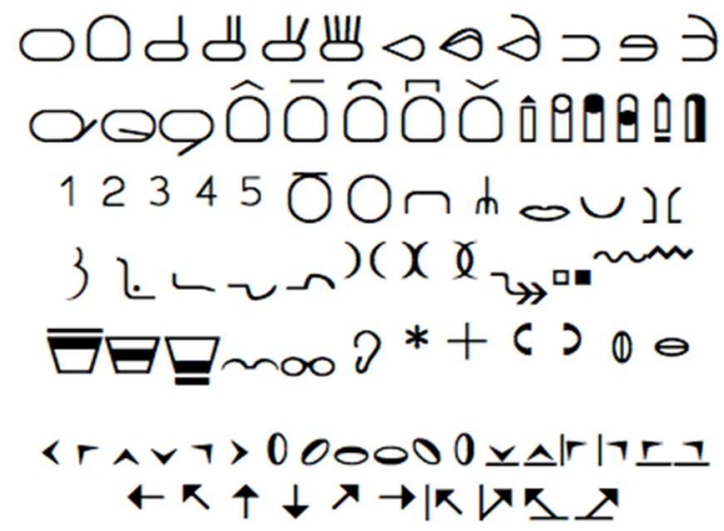

Figure 4. Symbol Set used in HamNoSys Notation System

\section{Tutorial for Hindi Alphabet}

Teaching Hindi alphabet to hearing impaired students is very hard because of lack of teaching resources. We have tried an attempt to produce the web portal which displays the Hindi alphabet along with a corresponding word for that alphabet. Along with the textual information (Hindi Alphabet and corresponding word), a picture of the word is also displayed. The computerized animation is produced in Indian Sign Language describing how to produce the sign for each word. For each Hindi alphabet, we have chosen two word for better understandability. For a total of 33 alphabets, we have created HamNoSys code for 66 words. HamNoSys has an alphabet of about 200 symbols (Unicode of this notation system is available) which covers almost all the hand shapes, hand location, hand/palm orientation, hand movement, and non-manual parts of the sign. Later this HamNoSys can be converted into SiGML (Signing Gesture Markup Language) tags which are sort of XML tags that can be animated by an animation tool using an Avatar. The sequence of steps for creating the animation from English word is as shown in Figure 5 [10]:

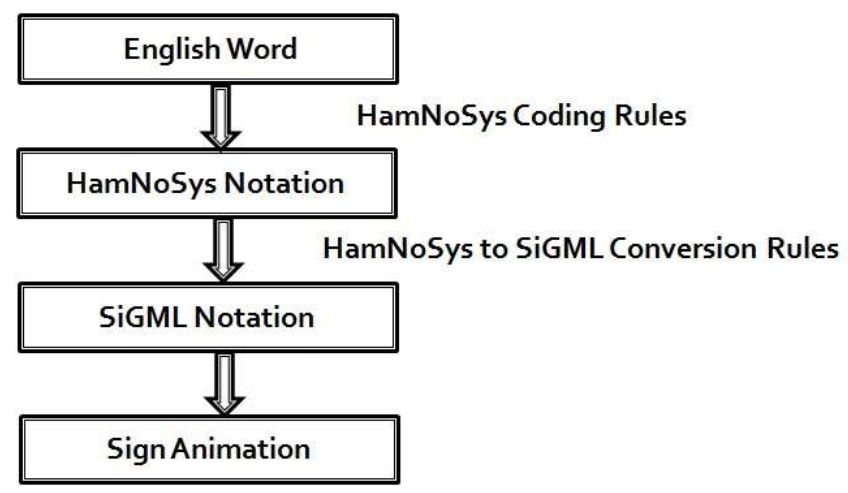

Figure 5. Architecture to Produce the Animation from English Word 
All the 66 signs are dynamic signs except the sign of word नाक (nose) which is static single handed sign. Table 2 shows the list of words corresponding to each Hindi alphabet.

Table 2. Words for each Alphabet coded in HamNoSys

\begin{tabular}{|l|l|l|l|}
\hline Hindi Alphabet & Words & Hindi Alphabet & Words \\
\hline क & कुता, कौआ & प & पंख, पाईप \\
\hline ख & खिड़की, ख़रगोश & फ & फूल, फल \\
\hline ग & गाय, गला & ब & बतख, बिल्ली \\
\hline घ & घोड़ा, घर & भ & भेंस, भोंकना \\
\hline च & चिड़ियाघर, चमड़ी & म & मछली, मेंढ़क \\
\hline छ & छतरी, छल्ला & य & यंत्र, यांत्रिक \\
\hline ज & जहाज, जुलाहा & र & रात, रोड़ा \\
\hline झ & झंडा, झरना & ल & लकडहारा, लोमड़ी \\
\hline ट & टमाटर, टोकरी & व & व्यापार, वेल्डर \\
\hline उ & ठठेरा, ठंड & श & शयन, श्नानघर \\
\hline ड & डिम्ब, डब्बा & ष & षटकोन \\
\hline ढ & ढाल, ढूढना & स & सेब, सुनना \\
\hline त & तरबूज, तार & ह & हथोड़ी, होंठ \\
\hline थ & थेला, थवई & क्ष & क्षेत्रजीव \\
\hline द & दर्जी, दुकान & त्र & त्रिशूल \\
\hline ध & धागा, धीवर & ज्ञ & ज्ञानी \\
\hline न & नाक, नाख़ून & & \\
\hline
\end{tabular}

\section{Conclusion}

Automatic tool for learning Hindi Alphabet by the hearing impaired people is challenging task because creation of synthetic animation for all the words corresponding to Hindi alphabets is very difficult. This paper represents the creation of synthetic animations using HamNoSys notation for 66 words for the entire Hindi alphabet. All the synthetic animations are incorporated in the web portal. The present work is important for hearing impaired people because of scarce resources like deaf schools in India. The tool can be very much beneficial for imparting education to these differently abled people.

\section{References}

[1] Ethnologue: Languages of the World. (2015). Retrieved July 10, 2016, from http://www.ethnologue.com/

[2] WFD | World Federation of the Deaf - World Federation of the Deaf, WFD, human rights, deaf, deaf people. (2015). Retrieved July 10, 2016, from https://wfdeaf.org/

[3] Disabled Population by type of Disability, Age and Sex - C20 Table. (2011.). Retrieved March 21, 2016, from http://www.censusindia.gov.in/2011census/C-series/c-20.html

[4] FDMSE-Indian SIGN LANGUAGE. Available from: http:// enabled.in/wp/indian-sign-language-dictionary-website/

[5] European sign language center. Available from: http://efsli. org/

[6] Handspeak. Available from: https://prezi.com/fugytefvya6z/httpwwwhandspeakcomwordwwhomp4/

[7] VCOM3D. Sign smith products. Available from: http:// www.vcom3d.com 


\section{Gyancity Journal of Engineering and Technology, \\ Vol.5, No.1, pp. 26-33, January 2019 \\ ISSN: 2456-0065 DOI: 10.21058/gjet.2019.51004}

[8] Hanke, T. (2004, May). HamNoSys-representing sign language data in language resources and language processing contexts. In LREC (Vol. 4).

[9] Kennaway, R. (2001, April). Synthetic animation of deaf signing gestures. In International Gesture Workshop (pp. 146157). Springer Berlin Heidelberg.

[10] Goyal, L., \& Goyal, V. (2016). Development of Indian Sign Language Dictionary using Synthetic Animations. In Indian Journal of Science and Technology, 9(32).

[11] JASigning. (2015). Retrieved October 15, 2016, from http://vh.cmp.uea.ac.uk/index.php/JASigning

Authors

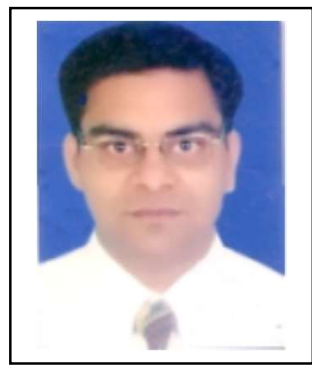

\section{Dr. Vishal Goyal}

Dr. Vishal Goyal (Ph.D., M.Tech., M.C.A., M.C.S.D.) is Associate Professor, Department of Computer Science, Punjabi University, Patiala, Punjab, India. His areas of research include Theory of Computation and Natural Language Processing. He has been awarded Young Scientist Award in 2005. He has in his credit one Copyrighted Software 'Hindi to Punjabi Machine Translation System' being used worldwide. Moreover, He is Chief Editor of the International Journal - Research Cell: An International Journal of Engineering Sciences, A Biannual, peer reviewed, refereed, indexed journal. He has into his credit about 100 research papers in various International and National journals of repute. He has delivered about 60 talks as Keynote Speaker/resource person in various reputed International and National Conferences and Workshops. He has guided about 80 M.Tech./M.Phil research scholars and guiding Ph.D. Scholars also. He has in his credit one Copyrighted Software 'Translator for English Text to ISL Synthetic Animations for Simple Sentences'.

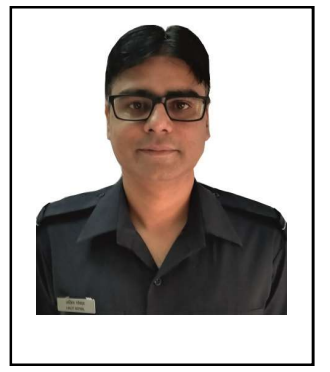

\section{Dr. Lalit Goyal}

Dr. Lalit Goyal (Ph.D., M.Tech., M.Phil.) is Associate Professor, Department of Computer Science, DAV College, Jalandhar, Punjab, India. His areas of research include Natural Language Processing and Digital Image Processing. He has into his credit about 18 research papers in various International and National journals and conferences. He has in his credit one Copyrighted Software 'Translator for English Text to ISL Synthetic Animations for Simple Sentences'. 